\title{
Health related quality of life in patients with chronic gastritis and peptic ulcer and factors with impact: a longitudinal study
}

Zhengwei Wen ${ }^{1}$, Xiaomei Li ${ }^{2}$, Qian $\mathrm{Lu}^{3}$, Julie Brunson ${ }^{4}$, Miao Zhao ${ }^{1}$, Jianfeng Tan ${ }^{5}$, Chonghua Wan ${ }^{5^{*}}$ and Pingguang Lei ${ }^{i^{*}}$

\begin{abstract}
Background: The assessment of Health Related Quality of Life (HRQOL) has been applied as a significant outcome indicator for patients with chronic diseases. No HRQOL study, however, has looked at HRQOL in patients with chronic gastritis and peptic ulcers. This paper focuses on comparing HRQOL in patients with chronic gastritis and peptic ulcers and examining the factors that influence the HRQOL of such patients. Results can be used for making decisions in clinical trials as well as aiding individual management and preventive care of these diseases.

Methods: The Chinese version of the SF-36 (CSF-36) was administered twice to 244 patients with chronic gastritis and peptic ulcers. Mean scores across the two disease groups were compared using t-tests, change over time was analyzed with paired samples t-tests, and factors predicting HRQOL were investigated using the univariate general linear model.

Results: The mean domain scores of patients with chronic gastritis were lower than those for patients with peptic ulcers, with the exception of physical functioning. Both groups had lower HRQOL compared with population norms. Mean domain scores increased after treatment in both groups. HRQOL in patients with these two chronic diseases differed by age, education level, marriage, income, and gender, but their explanatory power was relatively low.

Conclusion: Quality of life of patients with chronic gastritis was lower than that of patients with peptic ulcers, which was lower than population norms. Quality of life in both patients groups was associated with socio-demographic risk factors.
\end{abstract}

Keywords: Chronic digestive disease, Health-related quality of life, SF-36, Influence factors, Standardized response mean

\section{Background}

Diseases of the digestive system such as gastritis, functional gastrointestinal disorders, and peptic ulcers are common throughout the world [1-3]. While these are not generally life-threatening conditions, they can significantly impair patients' quality of life (QOL). These digestive system diseases are important to public health because they are remarkably common, can hinder a

\footnotetext{
* Correspondence: wanchh@hotmail.com; Ipg27548742@163.com

${ }^{5}$ School of Humanities and Management, Research Center for Quality of Life and Applied Psychology, Guangdong Medical College, Dongguan 523808, China

'People's Hospital of Songgang, Baoan, Shenzhen, Guangdong 518105, China

Full list of author information is available at the end of the article
}

person's daily activities, and can cause major social and economic burden. Peptic ulcer disease (PUD) affects as many as $10 \%$ of people in the United States at some point during their life, and the annual cost of treatment in the United States alone has been estimated at $\$ 5.7$ billion [1]. Thus, there is a substantial impact of these diseases on public health.

In the last 30 years, health-related quality of life (HRQOL) has become an important outcome measure for patients with cancer and chronic diseases. The Medical Outcomes Study 36-items Short-Form Health Survey (SF-36) has been widely used as a HRQOL instrument $[4,5]$ and is also being used with greater frequency internationally. The SF-36 has been translated into many

\section{Biomed Central}


foreign languages and is used in more than 40 countries as part of the International Quality of Life Assessment (IQOLA) project [5].

In China, research on HRQOL has sharply increased since the 1980s. The simplified Chinese (Mandarin) version of SF-36 (CSF-36) was rigorously developed using forward and backward translation and has demonstrated good reliability and validity in the Chinese general population [6]. More specifically, a three-stage protocol was followed including translation, tests of scaling construction and scoring assumptions, and validation and normalization. A total of 1688 respondents were recruited by multi-stage mixed sampling in 1000 households in 18 communities of Hangzhou. The results showed the clustering and ordering of item means was the same as that of the source survey. The item-scale correlations were identical for all except the social functioning and vitality scales; convergent validity and discriminant validity were satisfactory for all except the social functioning scale. In addition, Cronbach's $\alpha$ coefficients ranged from 0.72 to 0.88 , with the exception of 0.39 for the social functioning scale and 0.66 for the vitality scale, and two weeks test-retest reliability coefficients ranged from 0.66 to 0.94 . The translated survey was also able to distinguish between known groups. It was concluded that the Chinese (mainland) version of the SF-36 functioned in the general population quite similarly to the original American population tested [6].

In addition, the CSF-36 was validated among patients with chronic diseases including hypertension, coronary heart disease, chronic gastritis and peptic ulcers in China [7]. In this longitudinal study, the CSF-36 was used in a sample of 534 patients from these four chronic disease groups, and the psychometric properties of the scale were evaluated by indicators such as Cronbach's $\alpha$, Pearson's $r$, standardized response mean employing correlational analyses, multi-trait scaling analysis, t-tests, factor analyses, and structural equation models. It was concluded that the CSF-36 showed good validity and reliability but low responsiveness when used in patients, and it is a relatively useful instrument for patients with chronic disease when no specific instruments are available [7].

Worldwide, while there have been a few studies that used the SF-36 to measure HRQOL in patients with peptic ulcers [8-10], to date, there have been no studies which have compared HRQOL in patients with chronic gastritis and peptic ulcers using the SF-36. In a study conducted by Hallerbäck et al. [11], the Psychological General Well-Being Index (PGWB) was administrated to 1526 patients with esophagitis (192), gastric ulcers (109), duodenal ulcers (426), duodenitis/gastritis (296), negative endoscopy (401) and other diagnoses (102) before endoscopy. All five patient groups, excluding the other group, reported low general well-being compared to the general population; however, no differences emerged between the groups. On the other hand, in a study by Mokrowiecka et al. which used the SF-36, differences in HRQOL were found between patients with three common gastroenterological chronic conditions: gastroesophageal reflux disease (GERD), peptic ulcer disease (PUD) and ulcerative colitis (UC). Bodily pain measured by SF-36 was significantly lower in GERD and PUD than those with UC [8]. Therefore, we expect that SF-36 will allow the detection of different quality of life among patients with peptic ulcers and patients with chronic gastritis. We hope to fill a void in the literature by comparing these clinically similar diseases in an attempt to identify and explain differences in HRQOL outcomes. These results may be influential in making decisions in clinical trials as well as in aiding in the individual management of these diseases.

The goals of the present study are to (1) compare HRQOL using CSF-36 in patients with chronic gastritis and peptic ulcers, (2) compare HRQOL between both groups of patients and population norms, (3) determine the influence factors of HRQOL in these populations, and (4) compare HRQOL change over time and explore the factors that influence HRQOL differences after treatment.

\section{Methods \\ Patients}

Participants consisted of 244 inpatients with either chronic gastritis or peptic ulcers at the First Affiliated Hospital of Kunming Medical University. They were diagnosed primarily through endoscopy and gastric biopsy but also through gastrointestinal symptoms such as abdominal pain, bloating, and other symptoms of these two diseases. If any patients had both diseases, they were classified according to their primary diagnosis. All patients were considered for inclusion, but it was required that they were able to read, understand, and complete the questionnaires. Patients who were illiterate and those with advanced disease status were therefore excluded from participation.

\section{Measure}

The CSF-36 contains 36 items which represent eight domains: physical functioning (PF), role-physical (RP), bodily pain $(\mathrm{BP})$, general health $(\mathrm{GH})$, vitality $(\mathrm{VT})$, social functioning (SF), role-emotional (RE), and mental health $(\mathrm{MH})$. These domains can be further aggregated into a physical components summary (PCS) and a mental components summary (MCS), or an overall index if needed (see Figure 1) [12]. Specifically, all domain scores and the two component summaries are linearly converted into a $0-100$ scale using the following formula: $S S=($ RS-Min $) \times 100 / R$, where SS, RS, Min, and R represent the standardized score, 


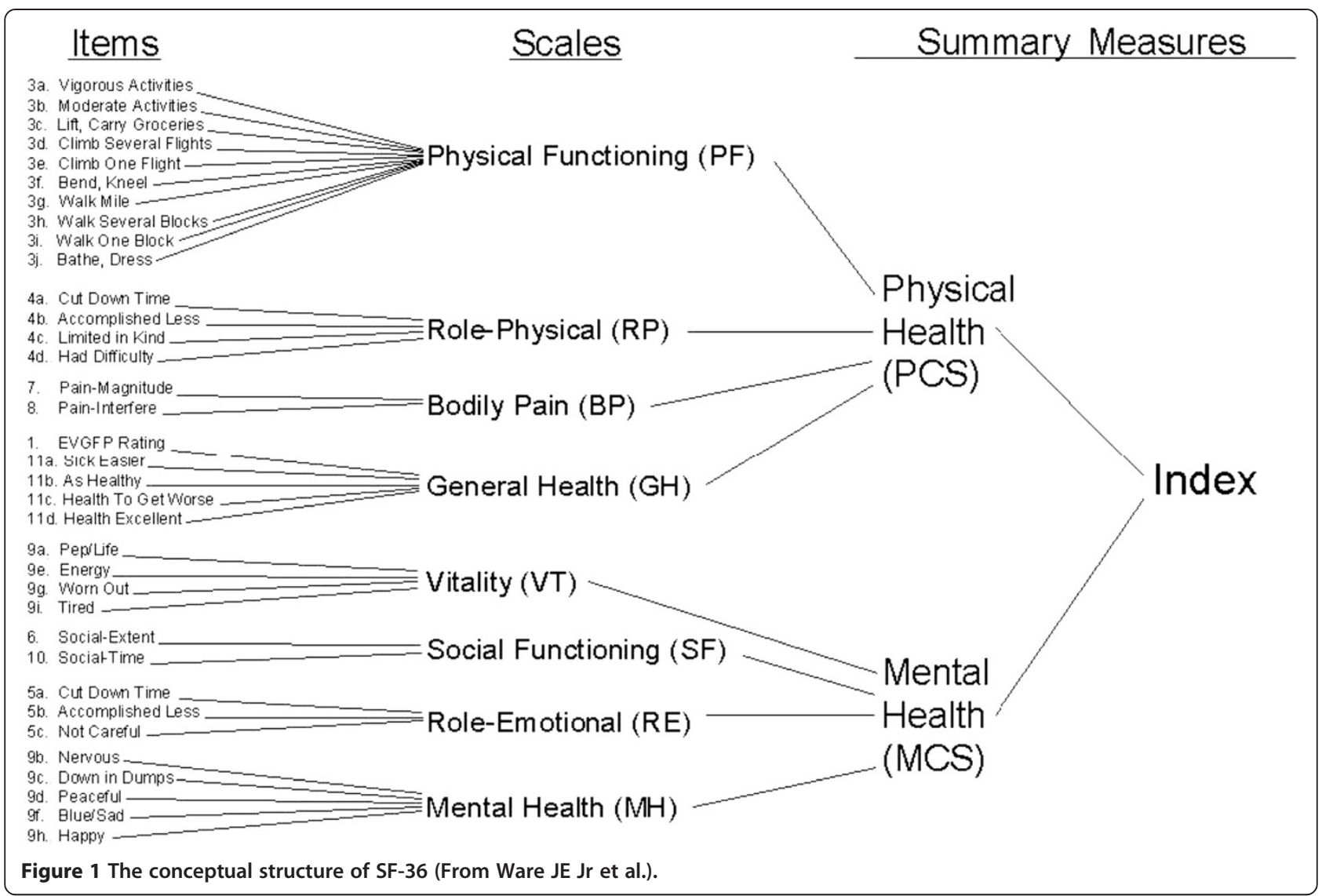

raw score, minimum score, and range of scores, respectively, with higher scores representing better HRQOL [12].

\section{Survey method}

After obtaining appropriate institutional review board approval of Kunming Medical University, the investigators described the study and the scale to the patients and obtained informed consent from patients who agreed to participate and met the inclusion criteria. Participants completed the CSF-36 (paper format) at the time of admission and at the time of discharge. Information regarding socio-demographic and clinical variables such as age, gender, and education was collected through medical records and the face page of our questionnaire.

\section{Statistical analysis}

Domain scores for each of the two diseases were compared using t-tests. Independent samples t-tests were used to compare the mean scores for each domain and summary variables of the CSF-36 at admission across the two disease groups. In addition, independent samples t-tests were used to compare differences in each domain between the two disease groups. The change of HRQOL scores from admission to discharge was evaluated in several different ways: with a paired sample t-test for each domain of the CSF-36 separately for each disease, with a change ratio $(\mathrm{CR}$, the difference between the two divided by the baseline means), and with a standardized response mean (SRM) $[13,14]$, used to reflect the degree of change. Of them, SRM was used as a measure of effect size, with values of $0.20,0.50$ and 0.80 representing small, moderate and large responsiveness respectively $[13,14]$.

In order to investigate what socio-demographic and disease type factors may influence HRQOL, the univariate general linear model was used with the information gathered at the time of admission (due to the larger sample size). PCS and MCS scores were used as the dependent variable respectively (backward selection with $\mathrm{p}$-value in $=0.05$ and $p$-value out $=0.10$ ), and age as the covariate. The categorical independent variables were recoded before analysis as follows: gender $(1=$ male, $2=$ female $)$, marriage $(1=$ married, $2=$ other $)$, education $(1=$ primary school, $2=$ high school, $3=$ college or higher), ethnicity $(1=$ Han, $2=$ other $)$, medical security $(1=$ self-pay or partly-pay, $2=$ public insurance), occupation $(1=$ factory worker, $2=$ other occupations), disease type $(1=$ chronic gastritis, 2 = peptic ulcer). Finally, the univariate general linear model was used to analyze HRQOL score change 
from admission to discharge with the PCS and MCS score change as the dependent variable respectively and factors above as independent variables.

\section{Results}

Socio-demographic characteristics of the study population

Table 1 summarizes the socio-demographic variables of interest in the current sample. Of the 244 patients who completed measures at admission, 124 had been diagnosed with chronic gastritis and 120 had been diagnosed with peptic ulcers. Ages ranged 16 to 79 , with a median age of 44.5 and mean $( \pm$ SD) age of $45.2( \pm 15.4)$. A majority of the patients were of Han ethnicity (86.9\%), male (58.2\%) and married (85.2\%). Forty-five patients (18.4\%) had finished primary school, while 119 (48.8\%) had completed high school, and 80 (32.8\%) had a college degree. Of those who completed the admission measures, $84.4 \%$ (206) also completed the measures at discharge (chronic gastritis, peptic ulcers).

Table 1 Socio-demographic characteristics of the sample

\begin{tabular}{|c|c|c|c|c|c|c|}
\hline \multirow[t]{2}{*}{ Characteristics } & \multicolumn{2}{|c|}{ Chronic gastritis $(\mathrm{N}=124)$} & \multicolumn{2}{|c|}{ Peptic ulcer $(\mathrm{N}=120)$} & \multicolumn{2}{|c|}{ Total $(\mathrm{N}=244)$} \\
\hline & $\mathrm{n}$ & $\%$ & $\mathrm{n}$ & $\%$ & $\mathrm{n}$ & $\%$ \\
\hline \multicolumn{7}{|l|}{ Gender } \\
\hline Male & 60 & 48.4 & 82 & 68.3 & 142 & 58.2 \\
\hline Female & 64 & 51.6 & 38 & 31.7 & 102 & 41.8 \\
\hline \multicolumn{7}{|l|}{ Marital status } \\
\hline Married & 103 & 83.1 & 105 & 87.5 & 208 & 85.2 \\
\hline Other & 21 & 16.9 & 15 & 12.5 & 36 & 14.8 \\
\hline \multicolumn{7}{|l|}{ Age } \\
\hline$<30$ & 28 & 22.6 & 18 & 15 & 46 & 18.9 \\
\hline $30-39$ & 32 & 25.8 & 19 & 15.8 & 51 & 20.9 \\
\hline $40-49$ & 17 & 13.7 & 27 & 22.5 & 44 & 18.0 \\
\hline $50-59$ & 23 & 18.5 & 32 & 26.7 & 55 & 22.5 \\
\hline$\geq 60$ & 24 & 19.4 & 24 & 20.0 & 48 & 19.7 \\
\hline $\bar{x} \pm S$ & & $43.7 \pm 15.6$ & & $46.7 \pm 15.2$ & & \\
\hline \multicolumn{7}{|l|}{ Ethnicity } \\
\hline Han & 108 & 87.1 & 104 & 86.7 & 212 & 86.9 \\
\hline Other & 16 & 12.9 & 16 & 13.3 & 32 & 13.1 \\
\hline \multicolumn{7}{|l|}{ Education } \\
\hline Primary school & 24 & 19.4 & 21 & 17.5 & 45 & 18.4 \\
\hline High school & 57 & 46.0 & 62 & 51.7 & 119 & 48.8 \\
\hline College/higher & 43 & 34.7 & 37 & 30.8 & 80 & 32.8 \\
\hline \multicolumn{7}{|l|}{ Occupation } \\
\hline Worker & 36 & 29.0 & 46 & 38.3 & 82 & 33.6 \\
\hline Farmer & 14 & 11.3 & 14 & 11.7 & 28 & 11.5 \\
\hline Teacher & 10 & 8.1 & 14 & 11.7 & 24 & 9.8 \\
\hline Office-bearer & 25 & 20.2 & 18 & 15 & 43 & 17.6 \\
\hline Others & 39 & 31.5 & 28 & 23.3 & 67 & 27.5 \\
\hline \multicolumn{7}{|c|}{ Perceived income } \\
\hline Poor & 25 & 20.2 & 35 & 29.2 & 60 & 24.6 \\
\hline Fair & 87 & 70.2 & 71 & 59.2 & 158 & 64.8 \\
\hline High & 12 & 9.7 & 14 & 11.7 & 26 & 10.7 \\
\hline \multicolumn{7}{|l|}{ Medical security } \\
\hline Self-paid & 51 & 41.1 & 41 & 34.2 & 92 & 37.7 \\
\hline Partly-pay & 7 & 5.6 & 6 & 5 & 13 & 5.3 \\
\hline Public insurance & 66 & 53.2 & 73 & 60.8 & 139 & 57.0 \\
\hline
\end{tabular}




\section{HRQOL comparisons across diseases}

At admission, the data from 244 patients (124 chronic gastritis and 120 peptic ulcers) were used to analyze HRQOL across diseases. As shown in Table 2 and Figure 2, most domains (with the exception of RP, BP, SF and PCS) exhibited statistically significance differences between the two disease groups. The patients with peptic ulcers had higher mean scores than those with chronic gastritis for most domains, with the exception of PF (where patients with chronic gastritis had higher scores).

In addition, based on the data from 206 patients (104 chronic gastritis and 102 peptic ulcers), mean scores for each domain and summary variable of the CSF-36 at discharge were compared (see Table 2). Only VT, MH, and MCS were significantly different between the two groups, with scores for patients with peptic ulcers being higher than those of patients with chronic gastritis.

\section{HRQOL comparisons between patients and population norms}

Work conducted in China with a community-based sample of 1688 showed mean domain scores of PF $82.2 \pm 19.8$, RP $81.2 \pm 33.6$, BP $81.5 \pm 20.5$, GH $56.7 \pm 20.2$, VT $52.0 \pm$ 20.9, SF $83.0 \pm 17.8$, RE $84.4 \pm 32.4$, and MH $59.7 \pm 22.7$ [6]. When compared to this normal sample, our sample showed (at admission) lower mean scores in seven domains for both patients with chronic gastritis and patients with peptic ulcers $(\mathrm{p}<0.001)$; there was no significant difference in $\mathrm{MH}$ scores for those with chronic gastritis and higher $\mathrm{MH}$ scores than that of the population norm for those with peptic ulcers.

\section{HRQOL change after treatments}

The mean duration of time between pre-and posttreatment assessments was $8.03 \pm 3.85$ days for chronic gastritis, and $7.11 \pm 2.86$ days for peptic ulcer. As shown in Table 3, the mean scores for most domains and for the two component summaries were significantly different before and after treatment (with the exceptions of $\mathrm{BP}$ and RE for chronic gastritis, and BP, SF, and RE for peptic ulcers). Overall, HRQOL changed more for patients with peptic ulcers than for patients with chronic gastritis, with most domains showing an increase except for RP in both patients with chronic gastritis and peptic ulcers. However, the only domains that were significantly different between the two disease groups were RP, RE, and $M H(p<0.05)$. For patients with chronic gastritis, the domains of PF, GH, and $\mathrm{MH}$, and also the PCS and MCS, had higher SRM $(>0.60)$ after treatment, indicating a moderate effect size. A possible reason for this is that these domains are largely affected by pain, and the pain was reduced after treatment.

Factors with impact on HRQOL

Results suggest that different domains of HRQOL are influenced by different socio-demographic variables as well as disease type (see Table 4). Higher PCS scores tended to be associated with patients who were married, younger, and had a higher education and income level. Higher MCS scores were associated with being male, having a higher education and income level, and having a peptic ulcer. For example, the PCS score for the married patients was on average 11.95 units higher than that of the other patients (single, divorced, etc.); the PCS score for the patients with education level one (primary school) was on average 11.70 units lower than that of the patients at education level three (college or higher) as suggested by the parameter coefficient of -11.70 . Similarly, the MCS score for male patients was on average 7.78 units higher than that of the female patients;

Table 2 Comparisons of mean scores $(\bar{X} \pm S)$ of domains of CSF-36 across two diseases at admission and discharge

\begin{tabular}{|c|c|c|c|c|c|c|}
\hline \multirow[t]{2}{*}{ Domains } & \multicolumn{3}{|c|}{ At admission $(n=244)$} & \multicolumn{3}{|c|}{ At discharge $(n=206)$} \\
\hline & $\begin{array}{l}\text { Chronic gastritis } \\
\qquad(n=124)\end{array}$ & $\begin{array}{l}\text { Peptic ulcer } \\
(n=120)\end{array}$ & $t$ & $\begin{array}{l}\text { Chronic gastritis } \\
\qquad(n=104)\end{array}$ & $\begin{array}{l}\text { Peptic ulcer } \\
(n=102)\end{array}$ & $t$ \\
\hline PF & $78.25 \pm 22.97$ & $71.22 \pm 28.91$ & $2.10^{*}$ & $87.65 \pm 16.71$ & $83.81 \pm 16.63$ & 1.64 \\
\hline $\mathrm{RP}$ & $33.67 \pm 39.69$ & $41.60 \pm 41.84$ & -1.52 & $30.77 \pm 38.51$ & $24.75 \pm 34.91$ & 1.17 \\
\hline BP & $52.27 \pm 20.86$ & $54.93 \pm 24.26$ & -0.92 & $51.92 \pm 20.02$ & $52.65 \pm 22.56$ & -0.24 \\
\hline GH & $43.06 \pm 19.67$ & $50.29 \pm 19.87$ & $-2.86^{*}$ & $51.25 \pm 18.71$ & $55.59 \pm 18.05$ & -1.69 \\
\hline VT & $49.40 \pm 21.10$ & $58.29 \pm 21.79$ & $-3.24^{*}$ & $55.14 \pm 19.31$ & $62.28 \pm 15.84$ & $-2.89^{*}$ \\
\hline SF & $70.79 \pm 23.52$ & $75.56 \pm 21.44$ & -1.65 & $74.15 \pm 21.70$ & $75.93 \pm 18.64$ & -0.63 \\
\hline RE & $38.98 \pm 41.80$ & $50.42 \pm 40.91$ & $-2.16^{*}$ & $46.15 \pm 41.88$ & $44.77 \pm 40.76$ & 0.24 \\
\hline MH & $60.03 \pm 20.39$ & $70.30 \pm 17.40$ & $-4.22^{*}$ & $67.73 \pm 18.05$ & $73.69 \pm 14.05$ & $-2.64^{*}$ \\
\hline PCS & $93.67 \pm 27.10$ & $95.22 \pm 31.56$ & -0.41 & $103.82 \pm 24.09$ & $103.35 \pm 21.62$ & 0.14 \\
\hline MCS & $56.89 \pm 18.51$ & $65.66 \pm 15.65$ & $-3.98^{*}$ & $63.19 \pm 17.07$ & $68.66 \pm 12.05$ & $-2.65^{*}$ \\
\hline
\end{tabular}

PF: physical function, RP: role-physical, BP: bodily pain, GH: general health, VT: vitality, SF: social function, RE: role-emotional, MH: mental-health, PCS: Physical Component Summary, MCS: Mental Component Summary. ${ }^{*} \mathrm{p}<0.05$. 


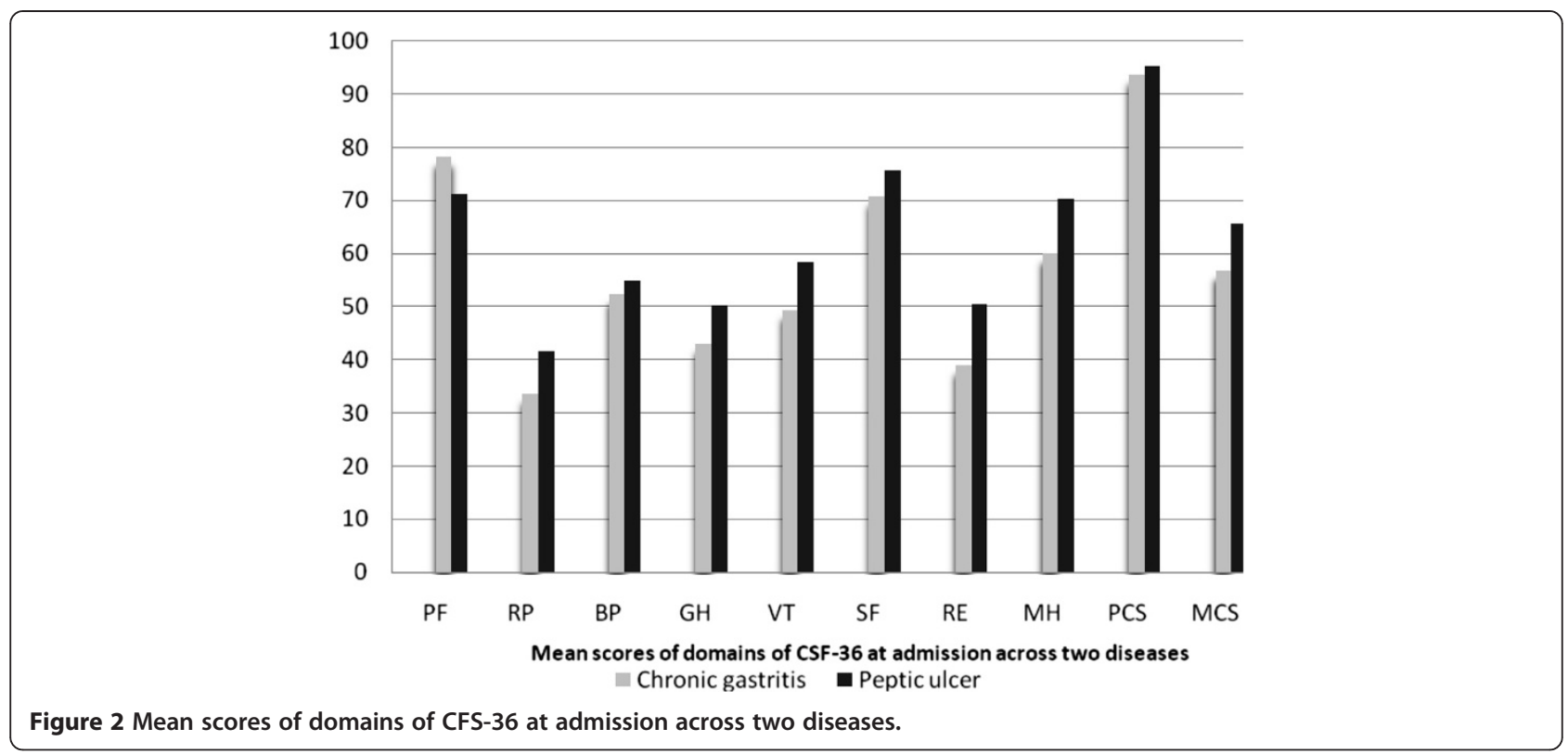

the MCS score for the patients with education level one (primary school) was on average 5.85 units lower than that of the patients at education level three (college or higher). However, it is noted that the MCS score for the patients with chronic gastritis was on average 7.48 units lower than that of the patients with peptic ulcers, given the other factors remain stable. This implies that the effects of the socio-demographic factors on PCS are the same across the disease types, but the effects of the factors on MCS scores were different. In other words, the effects of the factors on MCS were dependent on disease type, but the effects of the factors on PCS were not dependent on disease type.
The influence of the socio-demographic and disease type factors in predicting PCS and MCS score change after treatment were different from that above (see Table 5 in detail). Changes in PCS were influenced by marriage, age and occupation, whereas changes in MCS were only influenced by gender and marriage.

\section{Discussions}

The role of patient-based symptoms and QOL assessment in evaluating and treating gastrointestinal disorders has gained increased attention among gastrointestinal researchers in recent years. We found that patients with chronic gastritis had lower quality of life compared with

Table 3 CSF-36 domain score change after treatment for each disease

\begin{tabular}{|c|c|c|c|c|c|c|}
\hline \multirow[t]{2}{*}{ Domains } & \multicolumn{3}{|c|}{ Chronic gastritis } & \multicolumn{3}{|c|}{ Peptic ulcer } \\
\hline & $\operatorname{DIF}(\overline{\mathbf{X}} \pm \mathbf{S})$ & CR (\%) & $\overline{\text { SRM }}$ & $\operatorname{DIF}(\overline{\mathbf{X}} \pm \mathbf{S})$ & CR (\%) & $\overline{\text { SRM }}$ \\
\hline Physical functioning (PF) & $10.10 \pm 15.80$ & 12.93 & $0.64^{*}$ & $11.25 \pm 23.47$ & 15.53 & $0.48^{*}$ \\
\hline Role-physical (RP) & $-5.29 \pm 26.91 \#$ & -14.67 & $0.20^{*}$ & $-15.75 \pm 38.21 \#$ & -38.89 & $0.41^{*}$ \\
\hline Bodily pain (BP) & $-0.63 \pm 15.90$ & -1.21 & 0.04 & $1.82 \pm 19.76$ & -3.36 & 0.09 \\
\hline General health (GH) & $7.26 \pm 11.98$ & 16.50 & $0.61^{*}$ & $5.69 \pm 13.33$ & 11.39 & $0.43^{*}$ \\
\hline Vitality (VT) & $4.23 \pm 9.57$ & 8.31 & $0.44^{*}$ & $3.66 \pm 15.94$ & 6.25 & $0.23^{*}$ \\
\hline Social functioning (SF) & $3.53 \pm 15.03$ & 4.99 & $0.23^{*}$ & $-0.22 \pm 14.24$ & -0.29 & 0.02 \\
\hline Role-emotional (RE) & $3.21 \pm 30.29 \#$ & 7.46 & 0.11 & $-6.27 \pm 37.63 \#$ & -12.26 & 0.17 \\
\hline Mental health $(\mathrm{MH})$ & $7.12 \pm 11.37 \#$ & 11.74 & $0.63^{*}$ & $3.61 \pm 12.52 \#$ & 5.15 & $0.29^{*}$ \\
\hline PCS & $9.61 \pm 14.63$ & 10.13 & $0.66^{*}$ & $8.05 \pm 21.38$ & 8.46 & $0.38^{*}$ \\
\hline MCS & $5.33 \pm 8.69$ & 9.21 & $0.61^{*}$ & $2.93 \pm 10.10$ & 4.46 & $0.29^{*}$ \\
\hline
\end{tabular}

PCS: Physical Component Summary (weighted sum of PF, RP, BP and GH).

MCS: Mental Component Summary (weighted sum of VT, SF, RE and MH).

DIF: Difference between admission and discharge (scores at discharge minus scores at admission).

* $\mathrm{p}<0.05$ by paired t-test.

$\# \mathrm{p}<0.05$ by independent samples t-test. 
Table 4 Factors with impact on HRQOL in patients with chronic diseases selected by the univariate general linear models

\begin{tabular}{|c|c|c|c|c|c|}
\hline Domains & Factors & B & Std. error & $t$ & $P$ \\
\hline \multirow[t]{11}{*}{ Physical Component Summary (PCS) } & Constant & 123.78 & 7.93 & 15.61 & 0.000 \\
\hline & Marriage $=1$ (married $)$ & 11.95 & 5.47 & 2.13 & 0.030 \\
\hline & Marriage $=2$ (other) & . & . & . & . \\
\hline & Education = 1 (primary school) & -11.70 & 5.35 & -2.19 & 0.030 \\
\hline & Education = 2 (high school) & -1.63 & 4.05 & -0.40 & 0.688 \\
\hline & Education $=3$ (college or higher) & . & . & . & . \\
\hline & Perceived income $=1$ (poor) & -17.39 & 6.61 & -2.63 & 0.009 \\
\hline & Perceived income = 2 (fair) & -7.56 & 5.93 & -1.28 & 0.203 \\
\hline & Perceived income $=3$ (high) & . & . & . & . \\
\hline & Age & -0.60 & 0.13 & -4.66 & 0.000 \\
\hline & \multicolumn{5}{|c|}{ Adjusted R Square $=0.14 F=7.64, P=0.000$} \\
\hline \multirow[t]{12}{*}{ Mental Component Summary (MCS) } & Constant & 68.94 & 4.05 & 17.93 & 0.000 \\
\hline & Gender $=1$ (male) & 7.78 & 2.20 & 3.53 & 0.000 \\
\hline & Gender $=2$ (female) & . & . & . & . \\
\hline & Education = 1 (primary school) & -5.85 & 3.01 & -1.96 & 0.050 \\
\hline & Education = 2 (high school) & 2.38 & 2.43 & 0.98 & 0.328 \\
\hline & Education = 3 (college or higher) & . & . & . & . \\
\hline & Perceived income = 1 (poor) & -14.56 & 3.38 & -3.79 & 0.000 \\
\hline & Perceived income = 2 (fair) & -7.66 & 3.45 & -2.22 & 0.027 \\
\hline & Perceived income = 3 (high) & . & . & . & . \\
\hline & Disease $=1$ (chronic gastritis) & -7.48 & 2.14 & -3.50 & 0.001 \\
\hline & Disease = 2 (peptic ulcer) & . & . & . & . \\
\hline & \multicolumn{5}{|c|}{ Adjusted R Square $=0.17 F=9.09, P=0.000$} \\
\hline
\end{tabular}

B: Regression coefficient, Std Error: Standard error of Coefficients B.

Categories in bold were as references.

Table 5 Factors with impact on HRQOL change after treatments in patients with chronic diseases selected by the univariate general linear models

\begin{tabular}{|c|c|c|c|c|c|}
\hline Domains & Factors & B & Std. error & $t$ & $P$ \\
\hline \multirow[t]{7}{*}{ Physical Component Summary (PCS) } & Constant & 6.44 & 4.19 & 1.54 & 0.126 \\
\hline & Marriage $=1$ (married) & -8.15 & 3.94 & -2.07 & 0.040 \\
\hline & Marriage $=2$ (other) & . & . & . & . \\
\hline & Occupation =1 (worker) & 4.71 & 2.69 & 1.75 & 0.080 \\
\hline & Occupation $=2$ (other) & . & . & . & . \\
\hline & Age & 0.17 & 0.09 & 1.82 & 0.070 \\
\hline & \multicolumn{5}{|c|}{ Adjusted $\mathrm{R}$ Square $=0.03 \mathrm{~F}=2.92, \mathrm{P}=0.035$} \\
\hline \multirow[t]{6}{*}{ Mental Component Summary (MCS) } & Constant & 9.96 & 1.83 & 5.45 & 0.000 \\
\hline & Gender $=1$ (male) & -2.54 & 1.30 & -1.97 & 0.050 \\
\hline & Gender $=2$ (female) & . & . & . & . \\
\hline & Marriage $=1$ (married) & -5.09 & 1.80 & -2.82 & 0.005 \\
\hline & Marriage $=2$ (other) & . & . & . & . \\
\hline & \multicolumn{5}{|c|}{ Adjusted $R$ Square $=0.05, F=5.89, P=0.003$} \\
\hline
\end{tabular}


patients with peptic ulcers (except for PF domain), and both groups had lower quality of life compared with population norms (except for $\mathrm{MH}$ domain). Both groups experienced increased QOL after treatments (except for RP domain for two diseases). Patients who were female, with lower income, lower education, and older age tended to have lower quality of life.

Patients with peptic ulcers tended to be older than patients with chronic gastritis (with mean ages of 46.7 and 43.7 , respectively), which may explain the differences between groups, as increases in age are associated with a decline in physical functioning and an increase in mental functioning $[15,16]$. Another explanation is that the differences may be due to gender; there were more women than men in the chronic gastritis group and more men than women in the peptic ulcer group. Additionally, patients with chronic gastritis tended to be in worse health than those with peptic ulcers when they were hospitalized. However, to understand the cause of this, further study is needed. Future research should further examine the differences in HRQOL between the two groups as well as explore possible explanations for the differences.

Past work has shown that patients with chronic disease tend to have lower mean domain scores than the general population, due to the symptoms and side effects caused by treatments $[11,17,18]$. For example, in Hallerbäck's study [11], the results showed that all five patient groups with digestive diseases reported low general well-being compared with the general population. When compared to Chinese population norms [6], our sample also showed lower mean scores in seven domains for both patients with chronic gastritis and patients with peptic ulcers, (the only exception being $\mathrm{MH}$ ), which supports these existing findings.

In general, patients with gastrointestinal disorders tend to have lower QOL than the general population, and treatment of the disorder can improve QOL [16-21]. For example, Glise investigated 392 patients with peptic ulcers and found that the general QOL score for the PGWB increased significantly during treatment up until two weeks post-treatment [21]. The change in domain scores from admission to discharge reflects not only the effect of treatment but also the internal responsiveness of the instrument $[13,14]$. Table 3 shows that most domain scores changed greatly after treatment for both those with chronic gastritis and peptic ulcers (moderate and large SRM). The increase in domain scores after treatment would suggest greater QOL, however for patients in both disease groups the mean score of rolephysical declined. This decline may be explained by the nature of the instrument; 4 items $(4 a, 4 b, 4 c, 4 d)$ probe role limitations that are a result of physical health (e.g., "Cut down on the amount of time you spent on work or other activities"). Patients who just spent time in the hospital being treated are likely to respond affirmatively to these items.

It is notable that some domains (e.g. bodily pain, roleemotional) had no significant differences after treatment. Some possible explanations for this are: (1) the observation period (approximately two weeks) may have been too short to observe significant changes; (2) some domains may not change over time; (3) insufficient sample size; and (4) the CSF-36 may not be sensitive enough for use in work examining chronic disease, as it was developed for the general population [22].

Lower HRQOL scores have previously been associated with lower socioeconomic status, educational attainment, and age [23-27]. Our results supported these findings, as HRQOL was related to age, education, marriage, and disease type, although different domains were influenced by different factors. Overall, patients' education level and perceived income were the most influential factors, as those with a higher education level and with higher perceived income tended to have higher domain scores. The reason for this may be that the people with a higher education level and higher perceived income have better life conditions. HRQOL scores in patients living with a spouse were greater than those of patients without a spouse, which may be due to the additional support a patient may receive from a spouse versus other family members.

Patients with peptic ulcers tended to have higher scores on the mental component summary than those with chronic gastritis after controlling for other factors. There were also some observed gender effects, as male patients tended to have higher scores for the mental component summary after controlling for other factors, which is in accordance with other findings using the SF-36 [28,29]. Although systematic differences in HRQOL between men and women is a common finding, very few explanations or interpretations have been presented as to why this is the case. It may be that women experience greater, and/or different, stressors than the men. Ultimately, it is not clear why the effects of the socio-demographic factors on the mental component summary scores were dependent on disease type whereas the effects of the factors on physical component summary scores were not. Most likely, this is because there were differences in MCS scores across the two groups but no differences in PCS scores across the groups. Further research is needed to investigate the nature of these differences and their associated consequences. The factors influencing HRQOL also impacted longitudinal change after treatment. Changes in the physical component summary scores were influenced by marriage, age and occupation, whereas changes in the mental component summary scores were only influenced by gender and marriage. The reasons for these differences should be studied further. However, it should be noted that these 
factors had lower explanatory power for HRQOL as indicated by the relatively small adjusted R-squared $(0.14$ for PCS and 0.17 for MSC, 0.03 for PCS change and 0.05 for MCS change). We plan to investigate the effect of clinical variables such as disease stage, severity, and comorbidities in future studies.

It is important to note that the participants were only selected from a hospital and there was a fairly small sample size, which may be a limitation of the study. Additional community studies with larger sample sizes are needed. In addition, this study focused on HRQOL changes as indicated by statistical significance; however, clinically meaningful differences were not considered, which are more important than statistically significant differences. Our future directions include analyzing the minimal clinical important difference of QOL scores for these two diseases by anchor-based methods and distribution-based methods.

Despite these limitations, we found that patients with chronic gastritis had lower HRQOL than patients with peptic ulcers. Both groups had lower HRQOL at admission than the general population. In general, quality of life increased after treatment in both groups, and HRQOL in patients with these two chronic diseases differed by age, education level, marriage, income, and gender. Patients who were female, with lower income, lower education, and older age, tended to have a lower quality of life. Such information could be useful for making decisions in clinical trials as well as for individual management and rehabilitation of these diseases [30,31]. Well-executed HRQOL research such as this helps inform those tasked with health rationing or anyone involved in the decision-making process for agencies such as the Food and Drug Administration, European Medicines Agency or National Institute for Clinical Excellence [31].

\section{Conclusion}

In conclusion, this is the first study to investigate quality of life and its association with socio-demographic risk factors among Chinese patients with peptic ulcers and chronic gastritis. Future studies should investigate why quality of life is linked to socio-demographic factors and clinical factors.

\section{Competing interests}

The authors declare that they have no competing interests.

\section{Authors' contributions}

ZW, PL contributed to the design of the study, acquired and analyzed the data; $\mathrm{XL}$ contributed to the design of the study, analysis of the data and was involved in drafting the manuscript; QL contributed to the analysis of the data and revision of the manuscript; JB contributed to the analysis of the data and revision of the manuscript; $M Z$ contributed to data-acquirement and analysis; JT contributed to data-acquirement and analysis; CW contributed to design of the study, data-acquirement and drafted the manuscript. All authors have read and approved the final manuscript.
Authors' information

\# Zhengwei Wen and Xiaomei Li are as the first co-author with the same contributions.

\section{Acknowledgements}

In carrying out this research project, we have received substantial assistance from the staff of the First Affiliated Hospital of Kunming Medical University, including Zengfen Zhou, Liping Duan, Zhihuan Zhao, and investigators Li Gao, Xinping Huang and Ruixue Yang. We sincerely appreciate their kind help. In addition, we acknowledge Madeline Adams for proofreading.

\section{Grants}

Supported by the National Natural Science Foundation of China (30860248), the Key Discipline and Science \& Technology Innovation Fund of Guangdong Medical College (XZ1111, STIF201119).

\section{Author details}

'People's Hospital of Songgang, Baoan, Shenzhen, Guangdong 518105, China. ${ }^{2}$ School of Public Health, Kunming Medical University, Kunming, Yunnan 650031, China. ${ }^{3}$ Department of Psychology, University of Houston, Houston, TX 77204, USA. ${ }^{4}$ Department of Psychology, Pennsylvania State University, Pennsylvania, PA, USA. ${ }^{5}$ School of Humanities and Management, Research Center for Quality of Life and Applied Psychology, Guangdong Medical College, Dongguan 523808, China.

Received: 31 March 2013 Accepted: 12 August 2014

Published: 20 August 2014

\section{References}

1. Sonnenberg A, Everhart JE: Health impact of peptic ulcer in the United States. Am J Gastroenterol 1997, 92:614-620.

2. Borgaonkar MR, Irvine EJ: Quality of life measurement in gastrointestinal and liver disorders. Gut 2000, 47(3):444-454.

3. Choi MG, Jung HK: Health related quality of life in functional gastrointestinal disorders in Asia. J Neurogastroenterol Motil 2011, 17(3):245-251.

4. Stewart AL, Hays RD, Ware JE Jr, The MOS: Short-form general health survey. Reliability and validity in a patient population. Med Care 1988, 26:724-735

5. Ware JE Jr: SF-36 health survey update. Spine 2000, 25(24):3130-3139.

6. Li L, Wang HM, Shen Y: Chinese SF-36 health survey: translation, cultural adaptation, validation and normalization. J Epidemiol Community Health 2003, 57:259-263.

7. Yang Z, Li W, Tu X, Tang W, Messing S, Duan LP, Pan JH, Li XM, Wan CH: Validation and psychometric properties of Chinese version of SF-36 in patients with hypertension, coronary heart diseases, chronic gastritis and peptic ulcer. Int J Clin Pract 2012, 66(10):991-998.

8. Mokrowiecka A, Jurek K, Pińkowski D, Małecka-Panas E: The comparison of health-related quality of life (HRQL) in patients with GERD, peptic ulcer disease and ulcerative colitis. Adv Med Sci 2006, 51:142-147.

9. Gonzàlez-Stawinski GV, Rovak JM, Seigler HF, Grant JP, Kalady MF, Biswas S, Pappas TN: Poor outcome and quality of life in female patients undergoing secondary surgery for recurrent peptic ulcer disease. J Gastrointest Surg 2002, 6(3):396-402.

10. Ruta DA, Garratt AM, Russell IT: Patient centred assessment of quality of life for patients with four common conditions. Qual Health Care 1999, 8(1):22-29.

11. Hallerbäck B: Assessment of Quality of Life among patients with suspected duodenal ulcer. Scand J Gastroenterol Suppl 1993, 199:32-33.

12. Ware JE, Snow KK, Kosinski M: SF36 Health Survey Manual and Interpretation Guide. Boston, MA: New England Medical Center, The Health Institute; 1993.

13. Terwee CB, Dekker FW, Wiersinga WM, Prummel MF, Bossuyt PM: On assessing responsiveness of health-related quality of life instruments: guidelines for instrument evaluation. Qual Life Res 2003, 12(4):349-363.

14. Husted JA, Cook RJ, Farewell VT, Gladman DD: Methods for assessing responsiveness: a critical review and recommendations. J Clin Epidemiol 2000, 53(5):459-468.

15. Lin J, Zhang $\amalg$, Zheng SH, Cai G: Relationship between quality of life factors $s$ and Chinese medical syndromes in patients with chronic gastritis. Shanghai J Tradition Chinese Med 2006, 40(8):4-5. 
16. Mant JWF, Jenkinson C, Murphy MFG, Clipsham K, Marshall PO, Vessey MP: Use of the Short Form-36 to detect the influence of upper gastrointestinal disease on self-reported health status. Qual Life Res 1998, 7:221-226.

17. Cutts TF, Abell TL, Karas JG, Kuns J: Symptom improvement from prokinetic therapy corresponds to improved quality of life in patients with severe dyspepsia. Dig Dis Sci 1996, 41:1369-1378.

18. Moyer CA, Fendrick AM: Measuring health-related quality of life in patients with upper gastrointestinal disease. Dig Dis 1998, 16:315-324.

19. Wiklund I, Butler-Wheelhouse P: Psychosocial factors and their role in symptomatic gastroesophageal reflux disease and functional dyspepsia. Scand I Gastroenterol 1996, 31(Suppl 220):94-100.

20. Glise H: Quality of Life assessments in patients with peptic ulcer during treatment and follow-up. Scand I Gastroenterol Suppl 1993, 199:34-55.

21. Glise H, Hallerback B, Johansson B: Quality of Life assessments in the evaluation of gastroesophageal reflux and peptic ulcer disease before, during and after treatment. Scand J Gastroenterl 1995, 30(Suppl 208):133-135.

22. Wan $C H$, Tu XM, Messing $S$, Li XM, Yang Z, Zhao XD, Gao L, Yang YP, Pan $\mathrm{JH}$, Zhou ZF: Development and validation of the general module (QLICD-GM) of the system of quality of life instruments for chronic diseases and comparison with SF-36. J Pain Symptom Manage 2011, 42(1):93-104.

23. Wensing $M$, Vingerhoets $E$, Grol R: Functional status, health problems, age and comorbidity in primary care patients. Qual Life Res 2001, 10:141-148.

24. Woolf SH, Rothemich SF, Johnson RE: The functional status of inner-city primary care patients. Diminished function in a family practice population and its potential determinants. J Fam Pract 1998, 47:312-315

25. Sullivan M, Karlsson J: The Swedish SF-36 health survey III. Evaluation of criterion-based validity: results from normative population. J Clin Epidemiol 1998, 51:1105-1113.

26. Loge $J H$, Kaasa S: Short-form 36 (SF-36) health survey: normative data from the general Norwegian population. Scand J Soc Med 1998, 26:250-258

27. Jenkinson C, Layte R, Coulter A, Wright L: Evidence for the sensitivity of the SF-36 health status measure to inequalities in health: results from the Oxford healthy lifestyles survey. J Epidemiol Community Health 1996, $50: 377-380$

28. Jörngården $A$, Wettergen $L$, von Essen $L$ : Measuring health-related quality of life in adolescents and young adults: Swedish normative data for the SF-36 and the HADS, and the influence of age, gender, and method of administration. Health Qual Life Outcomes 2006, 4:91.

29. Raty LK, Wilde Larsson BM, Soderfeldt BA: Health-related quality of life in youth: a comparison between adolescents and young adults with uncomplicated epilepsy and healthy controls. J Adolesc Health 2003, 33(4):252-258.

30. Eiser C: Use of quality of life measures in clinical trials. Ambul Pediatr 2004, 4(4 Suppl):395-399.

31. Marquis P, Caron M, Emery MP: The Role of health-related quality of life data in the drug approval processes in the US and Europe: A review of guidance documents and authorizations of medicinal products from 2006 to 2010. Pharm Med 2011, 25(3):147-160.

doi:10.1186/1471-230X-14-149

Cite this article as: Wen et al:: Health related quality of life in patients with chronic gastritis and peptic ulcer and factors with impact: a longitudinal study. BMC Gastroenterology 2014 14:149.

\section{Submit your next manuscript to BioMed Central and take full advantage of:}

- Convenient online submission

- Thorough peer review

- No space constraints or color figure charges

- Immediate publication on acceptance

- Inclusion in PubMed, CAS, Scopus and Google Scholar

- Research which is freely available for redistribution

Submit your manuscript at www.biomedcentral.com/submit
C Biomed Central 